\title{
Pijat pada Ibu Postpartum dengan Onset Laktasi
}

\author{
Riana Andam Dewi ${ }^{1}$, Cia Aprilianti ${ }^{2}$ \\ ${ }^{1,2}$ Jurusan Kebidanan, Politeknik Kesehatan Kemenkes Palangka Raya, Indonesia \\ Email: riana.1041@yahoo.com
}

\begin{abstract}
Massage in Postpartum Mothers with Lactation Onset. Massage can be used as a non-pharmacological therapy to stimulate oxytocin to speed up the of onset lactation. If the onset of lactation happens quickly, then it should be breastfed as a baby's first nutrition life. This type of massage is a massage include massage lactation and oxytocin. The purpose of this study was to determine the difference in onset of lactation in postpartum mothers based on the type of massage given. The study design using Quasy Experiment, with the draft Non-Equivalent Control Group Design. The sampling technique was purposive sampling. The total sample was 40 mothers postpartum in Praktik Independent Midwive Ni Made Nuriasih and Praktik Independent Midwives Winanti in the city of Palangkaraya, then divided into 2 groups, 20 mothers postpartum performed postpartum maternal lactation massage and 20 mothers do massage oxytocin. A statistical test was using Independent T-test. The statistical analysis showed that mothers who do massage postpartum lactation had an average the onset of 35.05 hours of lactation. While the postpartum mother performed the oxytocin massage, there was a slower onset of lactation with an average of 49.14 hours. There was a significant difference in the average onset of lactation in postpartum women who performed lactation massage with postpartum mothers who performed oxytocin massage, where the onset of lactation in postpartum mothers performed lactation massage faster than postpartum mothers who performed oxytocin massage (p-value of 0.002). So, massage on postpartum mothers, especially lactation massage can be used as additional services to mothers after childbirth to facilitate the production and expenditure of breast milk, to support exclusive breastfeeding.
\end{abstract}

Keywords: Lactation massage and oxytocin massage, Lactation onset, Postpartum mothers

\begin{abstract}
Abstrak: Pijat pada Ibu Postpartum dengan Onset Laktasi. Pijat dapat dijadikan sebagai suatu terapi non-farmakologi untuk merangsang oksitosin agar mempercepat terjadinya onset laktasi. Jika onset laktasi terjadi dengan cepat, maka seharusnya bayi mendapatkan ASI sebagai nutrisi pertama kehidupannya. Jenis pijat yang dimaksud adalah pijat laktasi dan pijat oksitosin. Tujuan penelitian untuk mengetahui perbedaan onset laktasi pada ibu postpartum berdasarkan jenis pijat yang diberikan. Desain penelitian Quasy Eksperiment, dengan rancangan Non-Equivalent Control Group Design. Teknik pengambilan sampel secara purposive sampling. Jumlah sampel $40 \mathrm{ibu}$ postpartum di Praktik Mandiri Bidan (PMB) di Kota Palangka Raya, yaitu 20 ibu postpartum yang dilakukan pijat laktasi dan 20 ibu postpartum yang dilakukan pijat oksitosin. Uji statistik dengan menggunakan T-test Independent. Hasil penelitian menunjukkan ibu postpartum yang dilakukan pijat laktasi mempunyai rata-rata onset laktasi sebesar 35,05 jam. Sedangkan ibu postpartum yang dilakukan pijat oksitosin, onset laktasinya lebih lambat yakni dengan rata-rata 49,14 jam. Dengan nilai $p$-value 0,002 maka ada perbedaan yang signifikan. Ada perbedaan rata-rata onset laktasi pada ibu postpartum yang dilakukan pijat laktasi dengan ibu postpartum yang dilakukan pijat oksitosin, dimana onset laktasi pada ibu postpartum yang dilakukan pijat laktasi lebih cepat daripada ibu postpartum yang dilakukan pijat oksitosin. Jadi, pijat pada ibu postpartum khususnya pijat laktasi dapat dijadikan sebagai pelayanan tambahan pada ibu setelah melahirkan untuk memperlancar produksi dan pengeluaran ASI, untuk mendukung pemberian ASI secara eksklusif.
\end{abstract}

Kata kunci: Pijat laktasi dan pijat oksitosin, Onset laktasi, Ibu postpartum,

Profil kesehatan Indonesia tahun 2016 menunjukkan cakupan bayi yang mendapatkan ASI sampai enam bulan hanya sebesar $29,5 \%$. Angka ini masih jauh dari target nasional yaitu sebesar 80\%. Menurut Profil Kesehatan Provinsi Kalimantan Tengah tahun 2016, di provinsi
Kalimantan Tengah cakupan pemberian ASI Ekslusif pada bayi rata-rata hanya mencapai 20,5\%, dan khususnya di Kota Palangka Raya hanya sebesar 15,0\% (Dinkes Kalteng, 2017).

Tidak segeranya ASI keluar setelah melahirkan merupakan alasan ibu memberikan 
susu formula sehingga gagalnya pemberian ASI eksklusif. Penelitian Hruschka (2005) menyebutkan bahwa ibu dengan onset laktasi yang terlambat memiliki peluang lebih kecil untuk dapat memberikan ASI secara eksklusif selama 6 bulan. Onset laktasi adalah masa permulaan untuk memperbanyak air susu sampai air susu keluar pertama kali atau persepsi ibu kapan air susunya keluar (come in) yang ditandai payudara terasa keras, berat, bengkak sampai air susu atau kolostrum keluar (Hruschka, 2005). Dikatakan onset laktasi cepat jika ASI keluar $\leq 72$ jam. Keterlambatan onset laktasi dipengaruhi beberapa faktor menurut penelitian Rivers (2010) yaitu umur, paritas, jenis persalinan, berat badan lahir, IMD, kecemasan, pijat oksitosin, dan status gizi.

Tidak semua ibu postpartum dengan onset laktasi yang cepat, maka perlu dilakukan upaya untuk mempercepat onset laktasi agar dapat meningkatkan cakupan pemberian ASI eksklusif. Pijat pada ibu postpartum dapat dijadikan sebagai suatu terapi non-farmakologi untuk merangsang oksitosin agar mempercepat terjadinya onset laktasi, seperti pijat laktasi dan pijat oksitosin.

Pijat laktasi adalah pemijatan yang dilakukan pada beberapa bagian tubuh, yaitu kepala, leher, bahu, punggung, dan payudara. Sedangkan pijat oksitosin, pemijatan tulang belakang pada daerah punggung. Penelitian yang dilakukan oleh Tri Puspitoningrum pada tahun 2012 menyimpulkan bahwa ibu yang diberikan pijat oksitosin onset laktasinya dua kali lebih cepat dibandingkan dengan ibu yang tidak diberikan pijat oksitosin, namun masih belum terdapat penelitian tentang pijat laktasi terhadap onset laktasi. Maka tujuan penelitian ini secara umum adalah ingin mengetahui perbedaan onset laktasi pada ibu postpartum setelah dilakukan pijat laktasi dan pijat oksitosin. Tujuan khusus penelitian ini yaitu diketahuinya gambaran faktor-faktor yang mempengaruhi onset laktasi pada ibu postpartum, diketahuinya gambaran rata-rata onset laktasi ibu postpartum berdasarkan jenis pijat dan faktor risiko, serta diketahuinya perbedaan onset laktasi berdasarkan faktor risiko.

\section{METODE}

Desain penelitian yang digunakan dalam penelitian ini adalah metode Quasy Eksperiment dengan rancangan Non-Equivalent Control Group Design. Kelompok intervensi dalam penelitian ini adalah ibu postpartum yang dilakukan pijat laktasi sedangkan kelompok kontrol dalam penelitian adalah ibu postpartum yang dilakukan pijat oksitosin.

Jumlah sampel sebanyak 40 ibu postpartum di Praktik Mandiri Bidan Ni Made Nuriasih dan Praktik Mandiri Bidan Winanti di Kota Palangka Raya, yaitu 20 ibu postpartum yang dilakukan pijat laktasi dan 20 ibu postpartum yang dilakukan pijat oksitosin. Uji statistik dengan menggunakan T-test Independent.

\section{HASIL}

Penelitian dilakukan pada tanggal 5 Februari 2018 sampai dengan 20 Maret 2018 didapatkan sebanyak 22 reponden di PMB Ni Made Nuriasih sebanyak 18 reponden dan di PMB Winanti di kota Palangka Raya. Subyek penelitian ini adalah ibu postpartum dengan persalinan normal. Karakteristik dari 20 responden yang mendapatkan pijat laktasi dan 20 responden yang mendapatkan pijat oksitosin.

Tabel 1. Karakteristik Ibu Postpartum

\begin{tabular}{lcc}
\hline \multicolumn{1}{c}{ Karakteristik } & n & \% \\
\hline Jenis Pijat & & \\
$\quad$ Pijat Laktasi & 20 & 50 \\
$\quad$ Pijat Oksitosin & 20 & 50 \\
Umur & & \\
$20-30$ tahun & 21 & 52,5 \\
$\quad<20$ tahun & 5 & 12,5 \\
$\quad>30$ tahun & 14 & 35 \\
Paritas & & \\
$\quad$ Multipara & 26 & 65 \\
$\quad$ Primipara & 14 & 35 \\
Inisiasi Menyusu Dini & & \\
$\quad$ Ya & 22 & 55 \\
$\quad$ Tidak & 18 & 45 \\
Status Gizi & & \\
$\quad$ Normal & 25 & 62,5 \\
$\quad$ Underweight & 6 & 15 \\
Overweight & 7 & 17,5 \\
$\quad$ Obesitas & 2 & 5 \\
\hline
\end{tabular}

Dengan karakteristik responden sebagian besar umur antara 20-30 tahun yaitu sebanyak 21 responden (52,5\%), sedangkan responden dengan umur kurang dari 20 tahun sebanyak 5 responden $(12,5 \%)$, dan umur lebih dari 30 tahun sebanyak 14 responden (35\%). Paritas menunjukkan bahwa sebagian besar responden merupakan multipara yaitu sebanyak 26 responden $(65 \%)$ dan sebanyak 14 responden (35\%) adalah primipara. Inisiasi Menyusu Dini (IMD) menunjukkan bahwa responden yang tidak dilakukan IMD lebih besar yaitu sebanyak 22 reponden (55\%) dibandingkan yang dilakukan 
IMD yaitu 18 responden (45\%). Status gizi menunjukkan sebagian besar responden dengan IMT normal yaitu sebanyak 25 responden $(65,5 \%)$, sedangkan overweight sebanyak 7 responden $(17,5 \%)$, underweight sebanyak 6 responden $(15 \%)$, bahkan obesitas hanya sebanyak 2 responden $(5 \%)$.

Tabel 2. Observasi Onset Laktasi

\begin{tabular}{ccccc}
\hline Variabel & n & $\begin{array}{c}\text { Min- } \\
\text { Max }\end{array}$ & Mean & $\begin{array}{c}\text { 95\% CI } \\
\text { Mean }\end{array}$ \\
\hline $\begin{array}{c}\text { Onset } \\
\text { Laktasi }\end{array}$ & 40 & $15-78$ & 42,1 & $37,19-47,01$ \\
\hline
\end{tabular}

Hasil analisis univariat didapatkan ratarata onset laktasi responden adalah 42,1 jam, responden yang paling cepat terjadi onset laktasi pada 15 jam pertama setelah bayi lahir, sedangkan yang paling lambat pada 78 jam pertama setelah bayi lahir, untuk estimasi interval 95\% kita yakin bahwa rata-rata onset laktasi responden berada pada selang 37,19 jam sampai dengan 47,01 jam.

Tabel 3. Onset Laktasi pada Ibu Postpartum Berdasarkan Jenis Pijat

\begin{tabular}{|c|c|c|c|c|}
\hline \multirow{2}{*}{ Jenis Pijat } & \multicolumn{4}{|c|}{ Onset Laktasi (jam) } \\
\hline & $\mathbf{n}$ & Mean & SD & p-value \\
\hline Laktasi & 20 & 35,05 & 12,327 & 2. \\
\hline Oksitosin & 20 & 49,14 & 15,055 & 0,002 \\
\hline
\end{tabular}

Hasil analisis bivariat tersebut memperlihatkan bahwa ada 20 ibu postpartum yang dilakukan pijat laktasi mempunyai rata-rata onset laktasi sebesar 35,05 jam dengan standar deviasi 12,327 jam. Sedangkan ibu postpartum yang dilakukan pijat oksitosin, onset laktasinya lebih lambat yakni dengan rata-rata 49,14 jam dengan standar deviasi 15,055 jam. Dari hasil uji statistik menggunakan uji T-Test Independent dapat disimpulkan bahwa terdapat perbedaan yang bermakna antara onset laktasi pada ibu postpartum yang dilakukan pijat laktasi dibandingkan dengan ibu postpartum yang dilakukan pijat oksitosin $(p$-value $=0,002)$.
Tabel 4. Onset Laktasi pada Ibu Postpartum Berdasarkan Faktor Risiko

\begin{tabular}{lrrrr}
\hline & \multicolumn{4}{c}{ Onset Laktasi (jam) } \\
\cline { 2 - 5 } Faktor Risiko & $\mathbf{n}$ & Mean & \multicolumn{1}{c}{ SD } & $\begin{array}{c}\boldsymbol{p} \text { - } \\
\text { value }\end{array}$ \\
\hline Umur & & & & \\
20-30 tahun & 21 & 39,10 & 14,832 & \\
$\quad<20$ tahun & 5 & 39,80 & 9,654 & 0,278 \\
$\quad$ 30 tahun & 14 & 47,43 & 17,087 & \\
Paritas & & & & \\
$\quad$ Multipara & 26 & 43,58 & 17,186 & 0,356 \\
$\quad$ Primipara & 14 & 39,36 & 11,215 & \\
IMD & & & & \\
$\quad$ Ya & 22 & 35,68 & 12,249 & 0,002 \\
$\quad$ Tidak & 18 & 49,94 & 15,372 & \\
Status Gizi & & & & \\
$\quad$ Normal & 24 & 36,92 & 14,16 & \\
$\quad$ Underweight & 6 & 43 & 11,645 & 0,006 \\
$\quad$ Overweight & 7 & 53,14 & 12,402 & \\
$\quad$ Obesitas & 2 & 65,5 & 12,021 & \\
\hline
\end{tabular}

Responden berumur antara 20-30 tahun lebih banyak yaitu 21 ibu postpartum dengan rata-rata onset laktasinya 39,10 jam, sedangkan yang berumur lebih dari 30 tahun sebanyak 14 ibu dengan rata-rata onset laktasinya 47,43 jam, bahkan yang berumur kurang dari 20 tahun hanya 5 ibu yang rata-rata onset laktasinya adalah 39,80 jam. Dari hasil uji statistik menggunakan uji anova dapat disimpulkan bahwa tidak ada perbedaan yang signifikan ( $p$ value $=0,278$ ) antara onset laktasi pada ibu postpartum dengan umur $<20$ tahun, 20-30 tahun dan $>30$ tahun.

Ibu postpartum yang merupakan multipara lebih banyak yaitu 26 orang dengan rata-rata onset laktasi 21,15 jam dengan standar deviasi 12,186 jam, sedangkan ibu postpartum yang merupakan primipara sebanyak 14 orang dengan rata-rata onset laktasi 19,29 jam dengan standar deviasi 11,215 jam. Hubungan antara paritas dengan onset laktasi tidak mempunyai hubungan yang bermakna ( $p$-value $=0,356)$.

Ibu postpartum yang inisiasi menyusu dini (IMD) lebih cepat yaitu 35,68 jam dengan standar deviasi 12,249 jam, sedangkan rata-rata onset laktasi pada ibu postpartum yang tidak IMD adalah 49,94 jam dengan standar deviasi 15,372 jam. Hasil uji statistik didapatkan $p$ value $=0,002$, berarti dapat disimpulkan bahwa ada perbedaan rata-rata onset laktasi dengan inisiasi menyusu dini.

Sebagian besar status gizi responden berdasarkan pengukuran indeks massa tubuh adalah dalam kategori normal sebanyak sebanyak 25 orang dengan rata-rata onset laktasi 36,92 jam dan standar deviasi 14,16 jam. Kategori underweight sebanyak 6 orang dengan rata-rata 
onset laktasi 43 jam dan standar deviasi 11,645 jam. Kategori overweight sebanyak 7 orang dengan rata-rata onset laktasi 53,14 jam dan standar deviasi 12,402 jam. Sedangkan kategori obesitas hanya sebanyak 2 orang dengan rata-rata onset laktasi 65,5 jam dan standar deviasi 12,021 jam. Hasil uji statistik menggunakan uji anova didapatkan $p$-value $=0,006$, berarti dapat disimpulkan bahwa ada perbedaan rata-rata onset laktasi dengan status gizi.

\section{PEMBAHASAN}

\section{Perbedaan Onset Laktasi Berdasarkan Jenis Pijat}

Dari hasil penelitian pada 20 ibu postpartum yang dilakukan pijat laktasi $(50 \%)$ dan 20 ibu postpartum yang dilakukan pijat oksitosin $(50 \%)$ menunjukkan bahwa ibu yang dilakukan pijat laktasi terjadi onset laktasi lebih cepat dengan nilai rata-rata 35,05 jam, sedangkan yang dilakukan pijat oksitosin rata-rata onset laktasinya 49,14 jam. Terdapat perbedaan yang bermakna ( $p$-value $=0,002)$ antara pijat laktasi dan pijat oksitosin terhadap onset laktasi. Pada prinsipnya, kedua pijat ini ialah menimbulkan efek relaksasi untuk meningkatkan hormon oksitosin yang berperan sebagai hormon pengeluar ASI. Perbedaan onset laktasi yang bermakna dalam hal ini dapat disebabkan karena pada pijat laktasi dilakukan pemijatan pada lebih banyak titik pada bagian tubuh seperti di kepala, leher, bahu, punggung, dan payudara, serta durasi pemijatan yang lebih lama yaitu \pm 30 menit. Sedangkan pijat oksitosin dilakukan pemijatan hanya pada daerah punggung dengan durasi pemijatan selama \pm 15 menit. Kemudian dengan adanya pemijatan pada daerah payudara juga dapat lebih meningkatkan produksi dan pengeluaran ASI, karena menurut Hapitria (2017), jaringan payudara banyak berisi pembuluh getah bening dan pembuluh darah, pembuluh yang terhambat menjadi penyebab kurang lancarnya produksi dan aliran ASI.

\section{Perbedaan Onset Laktasi Berdasarkan Umur}

Dalam penelitian ini menyatakan bahwa tidak ada perbedaan rata-rata onset laktasi antara umur $<20$ tahun, 20-30 tahun dan >30 tahun dengan p-value 0,278. Pada penelitian sebelumnya oleh Sakha tentang The Onset Time Of Lactation After Delivery pada tahun 2005 juga menunjukkan bahwa tidak ada perbedaan rata- rata onset laktasi bersdasarkan umur ( $p$ value $=0,0555$ ).

Berbeda dengan hasil penelitian Rivers $e t$ al (2010) usia yang lebih dari 30 tahun secara signifikan dapat terjadi keterlambatan onset laktasi. Pernyataan ini dikemukakan disebabkan oleh umur yang lebih tua merupakan salah satu faktor risiko ketidaktoleran kadar karbohidrat selama kehamilan (Clausen et al 2005 dalam Hajerah 2015). Ketidaktoleran kadar karbohidrat selama kehamilan dapat mengakibatkan kadar gula ibu meningkat sehingga dapat mengakibatkan status gizi overweight. Dibuktikan juga dengan hasil penelitian Novitasari (2015) yang menyatakan bahwa ada hubungan umur ibu dengan onset laktasi pada ibu postpartum dengan tingkat hubungannya lemah.

Tidak ada perbedaan rata-rata onset laktasi yang bermakna ini dapat disebabkan karena jumlah responden dalam penelitian ini yang tergolong umur $<20$ tahun, 20-30 tahun dan $>30$ tahun tidak memiliki jumlah yang seimbang, dalam penelitian ini lebih banyak ibu postpartum dengan usia 20-30 tahun yaitu 21 responden, sedangkan usia >30 tahun sebanyak 14 responden bahkan usia $<20$ tahun hanya sebanyak 5 responden. Selain itu umur berhubungan dengan bagaimana presepsi ibu terhadap proses kehamilan dan kelahiran, tergantung dari ketahanannya atau kekuatan kepribadiannya, serta kemampuan yang dimilikinya (Puspita, 2013), yang mana hal ini berkaitan dengan faktor kecemasan. Kemudian umur juga berhubungan dengan status gizi, namun status gizi setiap ibu berbeda-beda tergantung pemenuhan kebutuhan nutrisi ibu tersebut.

\section{Perbedaan Onset Laktasi Berdasarkan Paritas}

Hasil penelitian menyebutkan bahwa kadar hormon kortisol pada ibu primipara 2 kali lebih banyak dibanding ibu multipara sehingga angka keterlambatan onset laktasi pada ibu primipara lebih tinggi (Grajeda, 2002). Didukung dengan penelitian Kesumaningsih (2012) yang menyatakan bahwa ibu primipara memiliki risiko onset laktasi lebih lama 5,4 kali dibandingkan dengan ibu multipara.

Namun dalam penelitian ini hubungan antara paritas dengan onset laktasi tidak ada perbedaan rata-rata yang bermakna ( $p$ value $=0,36)$. Hal ini dapat disebabkan karena jumlah responden yang merupakan multipara lebih banyak yaitu 26 responden (65\%) dibandingkan jumlah primipara yang hanya sebanyak 14 responden (35\%). Selain itu, 
menurut Atikah (2009) dalam Hajerah (2015) menyatakan bahwa paritas kecil hubungannya dengan produksi ASI yang diukur sebagai intake bayi terhadap ASI. Hal ini karena pemenuhan gizi bayi dan ibu setiap orang berbeda-beda. Apabila seorang ibu dengan pola hidup dan kebiasaan makan yang bergizi walaupun baru pertama kali melahirkan maka akan menghasilkan ASI yang bagus juga dibandingkan dengan ibu yang mempunyai anak lebih dari satu tanpa diimbangi dengan sistem kebiasaan makan yang baik.

\section{Perbedaan Onset Laktasi Berdasarkan Inisiasi Menyusu Dini}

Berdasarkan uji analisis menggunakan $T$ test independent seperti yang disajikan dalam tabel 4 menunjukkan bahwa terdapat perbedaan rata-rata IMD dengan onset laktasi ( $p$ value $=0,002$ ). Sejalan dengan penelitian yang dilakukan oleh Mawarti (2014) yang menyimpulkan bahwa Inisiasi Menyusu Dini (IMD) dapat mempercepat onset laktasi ( $p$ value $=0,000$ ). Waktu onset laktasi telah terbukti berhubungan dengan IMD karena menyusu dini akan memperlancar dalam pengenalan bayi akan puting ibu sehingga terjadinya onset laktasi berlangsung cepat. Apabila bayi tidak menghisap puting susu pada setengah jam setelah persalinan, hormon prolaktin dan hormon oksitosin akan sulit merangsang kembali produksi prolaktin sehingga ASI akan keluar pada hari ketiga atau lebih (Kristiyansari, 2009 dalam Hajerah, 2015).

\section{Perbedaan Onset Laktasi Berdasarkan Status Gizi}

Sesuai dengan hasil penelitian Dewey et al (2003), Hilson (2004), Rasmussen et al (2005), Rivers et al (2010), dan Hajerah (2015) yang menyatakan terdapat hubungan yang signifikan antara Indeks Massa Tubuh (IMT) dengan onset laktasi ibu postpartum. Penelitian ini juga menunjukkan bahwa ada perbedaan rata-rata onset laktasi yang signifikan terhadap status gizi berdasarkan hasil pengukuran IMT ( $p$ value $=0,006$ ). Kondisi individu yang overweight dan obesitas pada ibu postpartum berisiko terjadi keterlambatan onset laktasi yang mengakibatkan penurunan durasi menyusui ASI secara eksklusif (Rivers et al, 2009). Ibu yang memiliki status gizi overweight menyebabkan kadar progesteron yang tinggi, yang dimana setelah melahirkan kadar progesteron seharusnya menurun untuk merangsang sekresi prolaktin dalam memproduksi ASI. Namun karena kadar progesteron pada ibu yang memiliki status gizi overweight lebih tinggi sehingga dapat menghambat rangsangan produksi prolaktin, hal ini yang membuat onset laktasi lebih lama, dimana indeks massa tubuh mempunyai hubungan negatif dengan waktu laktogenesis II yaitu waktu sekresi onset laktasi (Rasmussen, 2005).

\section{SIMPULAN}

Ada perbedaan rata-rata onset laktasi pada ibu postpartum yang dilakukan pijat laktasi dan pijat oksitosin dengan $p$-value 0,002 . Rata-rata onset laktasi pada ibu postpartum yang dilakukan pijat laktasi lebih cepat yaitu 35,05 jam, sedangkan rata-rata onset laktasi pada ibu postpartum yang dilakukan pijat oksitosin yaitu 49,14 jam. Faktor yang mempengaruhi onset laktasi pada ibu postpartum seperti Inisiasi Menyusu Dini (IMD) menyatakan ada perbedaan rata-rata yang signifikan ( $p$-value $=0,002)$ dan status gizi pada ibu postpartum berdasarkan hasil pengukuran IMT juga menunjukkan bahwa ada perbedaan rata-rata onset laktasi yang signifikan ( $p$-value 0,006). Sedangkan faktor lain yang mempengaruhi onset laktasi seperti umur dan paritas tidak ada perbedaan rata-rata yang signifikan, dengan $p$-value berturut-turut yaitu 0,278 dan 0,356 .

\section{SARAN}

Perlu adanya peningkatan upaya pemberian pendidikan kesehatan oleh tenaga kesehatan khususnya bidan bagi ibu sejak awal kehamilan sampai dengan awal persalinan berhubungan dengan keberhasilan pemberian ASI eksklusif, sehingga dapat membantu ibu dalam memberikan ASI secara eksklusif kepada bayinya. Dan diharapkan pijat pada ibu postpartum, khususnya pijat laktasi dapat terus berlanjut menjadi pelayanan tambahan di Praktik Mandiri Bidan terkait maupun di pelayanan kesehatan lainnya dan penerapan proses inisiasi menyusu dini dilakukan semaksimal mungkin untuk membantu ibu dan bayi dalam proses menyusui. 


\section{DAFTAR PUSTAKA}

Dewey, Kathryn. 2003. Risk Factor for Subobtimal Infant Breasfeeding Behavior, Delayed Onset of Lactation and Excess Neonatal Weight Loss. Pediatrics. 112:607-619.

Dinas Kesehatan Provinsi Kalimantan Tengah. Profil Kesehatan 2016 Provinsi Kalimantan Tengah.

Grajeda \& Escamilla. 2002. Stress During Labour and Delivery Is Associated with Delayed Onset of Lactation among Urban Guatemala Women. The Jurnal of Nutrition. 132:3055-3060.

Hajerah. 2015. Hubungan Status Gizi dengan Onset Laktasi pada Ibu Postpartum di RS PKU Muhammadiyah Yogyakarta. [Skripsi]. Yogyakarta: Sekolah Tinggi Ilmu Kesehatan 'Aisyiyah.

Hapitria, Pepi. 2017. Pijat Laktasi. Pelatihan Metodik Khusus Clinical Instruktur Poltekkes Kemenkes Palangka Raya pada tanggal 29 April 2017.

Hilson, J.A., Rasmussen, K.M. \& Kjolhede, C.L. 2004. High Preepregnant Body Mass index is Associated with poor Lactation Outcomes among White, Rural Women Independent of Psychosocial and Demographic Correlates. J Hum Lact, 20 (1), 18-29.

Hruschka, et al. 2005. Delayed Onset Laktasion And Of Ending Full Breastfeeding Early In Rutal Guatemala. The Journal of Nutrition. 133:2592-2599.

Johnson, Ruth. 2004. Buku Ajar Praktik Kebidanan. Jakarta: EGC. Online: (http://kin.perpusnas.go.id/DisplayData.as px?pId=66\&pRegionCode $=$ PLKSBIDJ \&p ClientId=141) diakses pada tanggal 1 November 2017.

Kementerian Kesehatan Republik Indonesia. Data dan Informasi Profil Kesehatan Indonesia 2016. Jakarta.

Kesumaningsih, Fitriyana \& Ida Nursanti. 2012. Onset Laktasi Terlambat Sering Terjadi pada Primipara. Media Ilmu Kesehatan. Vol. 1, No. 3.
Lain, K.Y. \& Catalano, P.M. 2007. Metabolic Changes in Pregnancy. Clin Obsted Gynecol.50: 938-948.

Mawarti, Retno. 2014. Inisiasi Menyusu Dini Mempercepat Onset Laktasi. Jurnal Kebidanan dan Keperawatan, Vol. 10, No. 2, Desember 2014: 199-206.

Novitasari, Hepy. 2015. Hubungan Umur Ibu dengan Onset Laktasi pada Ibu Postpartum di Rumah Sakit PKU Muhammadiyah Yogyakarta. [Naskah Publikasi]. Yogyakarta: Sekolah Tinggi Ilmu Kesehatan 'Aisyiyah.

Pace, B. 2001. Breastfeeding. The Journal Of The America Medical Assoiation.

Puspita, Rizki Lia. 2013. Kecemasan Menghambat Onset Laktasi Ibu Postpartum. Media Ilmu Kesehatan. Vol.2, No.3.

Puspitoningrum, Tri. 2012. Pengaruh Pijat Oksitosin terhadap Onset Laktasi pada Ibu Postpartum di RSUD Panembahan Senopati Bantul. [Skripsi]. Yogyakarta: Sekolah Tinggi Ilmu Kesehatan Jenderal Achmad Yani.

Rasmussen \& Kjolhede. 2005. Prepregnant Overweight and Obesity Diminish the Prolactin Response to Suckling in the Firs Week Postpartum. American Academy Pediatrics.

Rivers, L.A.N., Chantry, C.J., Peerson, J.M., Cohen, R.J., Dewey, K.G. 2010. Delayed Onset Of Lactogenesis Among Firsttime Mothers Is Related To Maternal Obesity And Factors Associated With Ineffective Breastfeeding. Am J Clin Nutr. 92:574584.

Rivers, L.A.N., Mastergeorge, A.M. \& Dewey, K.G. 2009. Doula Care, Early Breastfeeding Outcomes, and Breastfeeding Status at 6 Weeks Postpartum Among Low-Income Primiparae The Assocition of women's Health. Obestric And Nurses. 38:157-173.

Sakha, K. 2005. The Onset Time Of Lactation After Delivery. MJIRI, Vol.19, No.2, 135139. 